\title{
Aspectos morfológicos dos órgãos genitais femininos do gambá (Didelphis sp.)
}

\author{
Natalia Nardelli \\ GONÇALVES ${ }^{1}$ \\ Celina Almeida Furlanetto \\ MAÇANARES 2,3 \\ Maria Angélica MIGLINO3 \\ Vivian Yoshiko SAMOTO ${ }^{3}$ \\ Daniele dos Santos \\ MARTINS ${ }^{2,3}$ \\ Carlos Eduardo AMBRÓSIO ${ }^{3}$ \\ Rosa Helena dos Santos \\ FERRAZ $^{4}$ \\ Ana Flávia de CARVALHO²
}

\section{Correspondência para:}

Profa. Dra. Ana Flávia de Carvalho, Departamento de Ciências Morfológicas do Centro Universitário da Fundação de Ensino Octávio Bastos, Avenida Doutor Octávio Bastos s/n, Jardim Nova São João 13874148 - São João da Boa Vista-SP, labvet01@unifeob.edu.br

Recebido para publicação: 25/05/2006 Aprovado para publicação: 29/06/2009

\author{
1 - Curso de Ciências Biológicas do Centro Universitário da Fundação de Ensino \\ Octávio Bastos, São João da Boa Vista-SP \\ 2 - Departamento de Ciências Morfológicas do Centro Universitário da Fundação \\ de Ensino Octávio Bastos, São João da Boa Vista-SP \\ 3 - Faculdade de Medicina Veterinária e Zootecnia da Universidade de São Paulo, \\ São Paulo-SP \\ 4- Faculdade de Agronomia e Medicina Veterinária da Universidade Federal do \\ Mato Grosso, Cuiabá-MT
}

\section{Resumo}

Foram coletados oito sistemas reprodutores de fêmeas de gambás (Didelphis sp). Destes cinco, foram destinados ao estudo macroscópico e três ao estudo microscópico. Estes animais encontravam-se fixados no Departamento de Anatomia da UNIfeob, em formaldeído a 10\%, provenientes do Criatório Científico de Araçatuba (IBAMA). Para análise macroscópica, os sistemas reprodutores foram retirados, guardando-se as devidas posições "in situ" e foi realizada a documentação fotográfica para resultados macroscópicos. Para o estudo microscópico, o sistema reprodutor foi processado rotineiramente pela técnica de inclusão em Paraplast e cortadas em micrótomo, com espessura média de $5 \mathrm{~mm}$, e os cortes foram corados em HE, Azul de Toluidina, Picrosírius, PAS e tricromo de Masson ${ }^{16}$, ${ }^{17}$. O sistema reprodutor feminino do gambá era composto por dois ovários, útero duplo, duas vaginas laterais e entre estas um canal pseudovaginal, estas três estruturas se unem formando o seio urogenital encerrando em um "monte" púbico ou tubérculo genital, formando uma abertura comum interna ao ânus e a vulva, chamada de pseudocloaca ou seio urogenital. Microscopicamente os ovários eram funcionais com folículos mono e poliovulares. A tuba uterina era característica, revestida por epitélio prismático ciliado. Os cornos uterinos apresentaram epitélio de revestimento prismático ciliado. $\mathrm{O}$ seio urogenital apresentou três estruturas tubulares. A vulva apresentou as mesmas características da pele.

\section{Introdução}

Metatheria (Marsupialia) é um grupo formado por sete ordens, 19 famílias e 81 gêneros, contendo inúmeras espécies. Encontra-se assim organizado com base em semelhanças anatômicas e fisiológicas, particularmente relacionadas à reprodução. ${ }^{1,2}$

Não ocorre diapausa embrionária no gambá cinza de rabo - curto (Monodelphis domestica). A prenhez é muito curta, de apenas 12 dias após a cópula, impossibilitando este processo. $3,4,5$
Palavras-chaves: Gambá. Didelphis. Reprodução. Morfologia.
Entre os cangurus vermelhos a primeira prenhez da estação é seguida por uma gestação de 33 dias, após a qual o filhote dirige-se até o marsúpio sem auxílio da mãe prendendo-se a uma papila mamária. A mãe engravida imediatamente após, mas a presença de um filhote sendo amamentado dentro do marsúpio suspende o desenvolvimento do novo embrião dentro do útero, aproximadamente no estágio de 100 células. Este período de desenvolvimento suspenso é denominado diapausa embrionária e dura aproximadamente 235 dias. $^{4}$ 
O período gestacional médio é de 12 dias, podendo variar de cinco a 13 dias, nascendo em média de 10 a 15 filhotes por ninhada, sendo sua estimativa de vida de 2 a 4 anos. Quando os marsupiais nascem, eles devem deixar o órgão genital da fêmea para se prender a um mamilo completando seu desenvolvimento. $\mathrm{O}$ marsúpio não está presente em alguns dasiurídeos (camundongo marsupial, etc) e em alguns didelfídeos (gambás). Alguns didelfídeos apresentam filhotes mais altriciais que os cangurus. Estes embriões são expulsos do órgão genital da fêmea diretamente para a bolsa (ou para a área mamária de espécies sem a bolsa) ao nascimento. O tempo que os filhotes marsupiais passam em desenvolvimento, enquanto presos à glândula mamária (papila mamária), excede amplamente o período de gestação. ${ }^{4,6,7}$

A anatomia dos órgãos genitais das fêmeas marsupiais, quando comparada a outros mamíferos eutheria, tem muitos aspectos diferentes; o útero é duplo e é paralelo, mas está completamente separado um do outro, cada corno uterino possui uma cérvix e ambas se abrem no seio vaginal. O canal vaginal é uma das partes mais interessantes do órgão genital dessas fêmeas, pois consiste em duas vaginas laterais que se estendem até a pseudovagina (canal do parto) e chegam ao seio urogenital. $3,8,9,10$

As vaginas laterais possuem várias funções durante o parto e na cópula quando o sêmen passa através delas. A existência de duas vaginas influenciou o desenvolvimento do pênis e em muitos marsupiais, a glande do pênis é uma estrutura proeminente e bifurcada adequando-se a elas. ${ }^{11,12,13,14,15}$

Portanto, este trabalho teve por objetivo, estudar os aspectos anatômicos e histológicos dos órgãos genitais femininos do gambá (Didelphis sp.) que caracteriza esse gênero sul-americano e fornece subsídios morfológicos para investigações futuras sobre ocorrência ou não do fenômeno de diapausa, neste gênero, visto que este evento ainda não foi descrito para esse gênero.

\section{Material e Método}

Para a realização desta pesquisa foram colhidos oito órgãos genitais femininos de gambás (Didelphis sp), sendo cinco destinados ao estudo macroscópico e três ao estudo microscópico. Estes animais já estavam fixados em formaldeído a $10 \%$ provenientes do Criatório Científico de Araçatuba (IBAMA). Para análise macroscópica, os órgãos genitais foram esalados, dissecados e encaminhados para o laboratório de Morfologia Animal da UNIfeob, onde foram documentados digitalmente através de câmera digital Sony Mavica 3.2 megapixels (MP) e mediante desenho esquemático.

Para o processamento microscópico, segmentos das diferentes partes dos órgãos genitais foram retirados e pós-fixados em solução de paraformaldeído a 4 \% em tampão fosfato de sódio. (Dulbecco's phosfate buffer saline-DPBS, Gibco Co., USA). Posteriormente o material foi desidratado em uma série crescente de etanóis (de 70 a 100\%) e diafanizado em xilol, seguido de inclusão em similar de parafina (Histosec ${ }^{\circledR}$, Merk, lote: K91225309), conforme procedimento padrão7. Em micrótomo LEICA RM 2165, os materiais foram cortados com espessura média de 5 micrômetros (mm). Após a montagem das lâminas, os cortes foram corados pela hematoxilina-eosina (H.E), azul de toluidina, tricromo de Masson ${ }^{16} \mathrm{e}$ picrosírius 17. Também foram submetidos a reação histoquímica pelo ácido periódico-reativo de Schiff (PAS) com fundo de hematoxilina de Harris.

\section{Resultados e Discussão}

Os ovários, macroscopiacamente, eram ovóides, pequenos em relação aos dos caninos domésticos de mesmo porte, localizados na bolsa ovárica, na porção mais cranial da tuba uterina e lateralmente a bexiga urinária (Figura 1). ${ }^{1}$ Microscopicamente, em todos os animais estudados, foram obsevados 


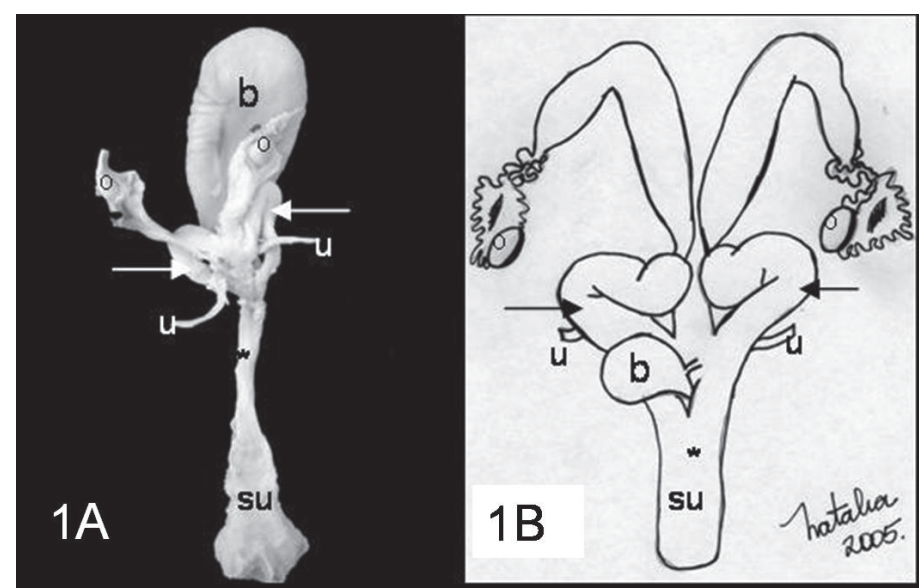

Figura 1 - Em 1A - Fotografia panorâmica da vista dorsal dos órgãos genitais femininos do gambá. Notar a bexiga (b), ovários (o), vagina lateral (setas), canal da pseudovagina $\left(^{*}\right)$ e o seio urogenital (SU). Em 1B Esquema dos órgãos genitais femininos do gambá, vista ventral. Notar o útero duplo (setas cheias), os ovários $(\mathrm{O})$, as vaginas laterais (setas finas), o ureter (u), a bexiga (b), a pseudovagina $\left({ }^{*}\right)$ e o seio urogenital (SU). Figura adaptada a partir de Harder, Stonerook e Pondy 11

folículos monovulares e folículos poliovulares, em diferentes fases de desenvolvivento conforme descrições na literatura. ${ }^{12}$ Os folículos apresentaram pouco antro e os ovócitos eram grandes e repletos de vitelo. $\mathrm{O}$ ovário era envolto externamente por epitélio simples cúbico (Figura 2).

As tubas uterinas ligadavam-se à bolsa

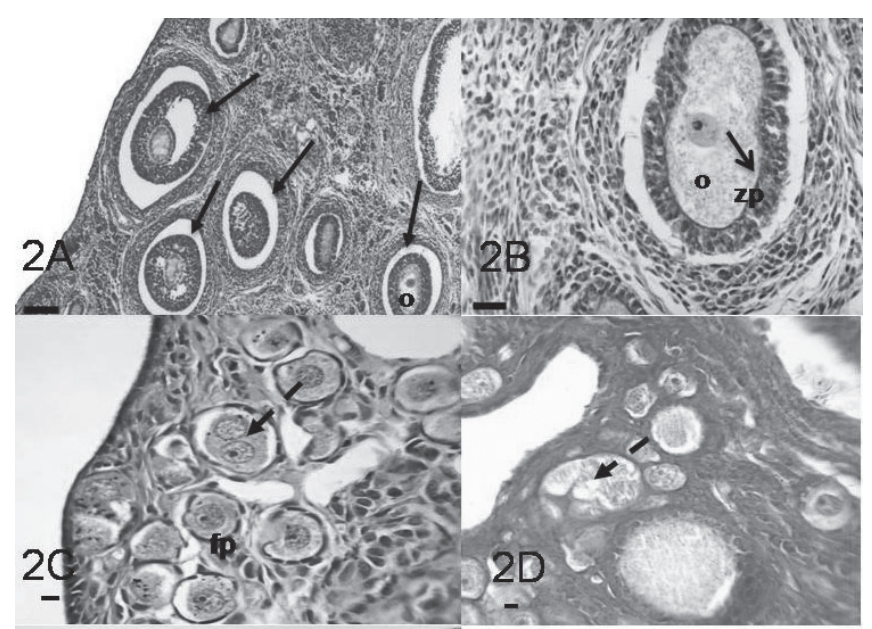

ovárica cranialmente e ao corno uterino mais caudalmente. Macroscopicamente possuíam coloração clara e formato enovelado e eram recobertas por tecido conjuntivo. Microscopicamente eram semelhantes às de outras espécies de mamíferos. ${ }^{8,13,14}$ Apresentaram epitélio de revestimento interno do tipo prismático baixo ciliado e em algumas de suas regiões havia células secretoras não ciliadas; a lâmina própria compunha-se de tecido conjuntivo frouxo; a camada muscular lisa apresentava as seguintes túnicas, circular interna e longitudinal externa; a serosa era espessa (Figura 3).

$\mathrm{O}$ útero dos marsupiais é do tipo duplo caracterizado por duas cérvix independentes, difereindo da classificação bicornuada encontradas na literatura. ${ }^{711}$

Histologicamente o útero era constituído por três camadas,

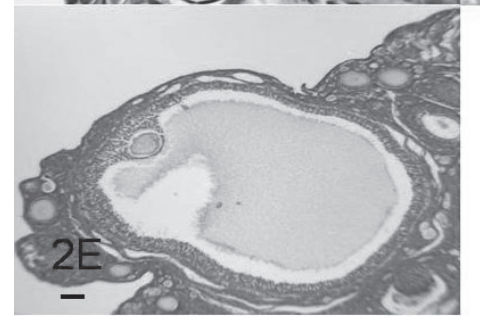

Figura 2 - Em 2A - Fotomicrografia do ovário. Notar folículos em crescimento (setas). $\mathrm{HE}$, barra $=90 \mu \mathrm{m}$. Em $2 \mathrm{~b}$ - Fotomicrografia do ovário. Notar um folículo em crescimento, evidenciando zona pelúcida (zp-seta) e ovócito rico em vitelo o citoplasma (o) reação histoquímica de PAS, barra $=20 \mu \mathrm{m}$. Notar na fotomicrografia $2 \mathrm{C}$ um folículo poliovular (seta) e folículo primordial $(\mathrm{fp}) \mathrm{HE}$, barra $=20 \mu \mathrm{m}$. Na fotomicrografia 2D folículo poliovular (seta pontilhada) picrosírius, $20 \mu \mathrm{m}$. Na fotomicrografia $2 \mathrm{~F}$ visão panorâmica de um folículo maduro prestes a ovular, picrosírius, barra $=11 \mu \mathrm{m}$ 


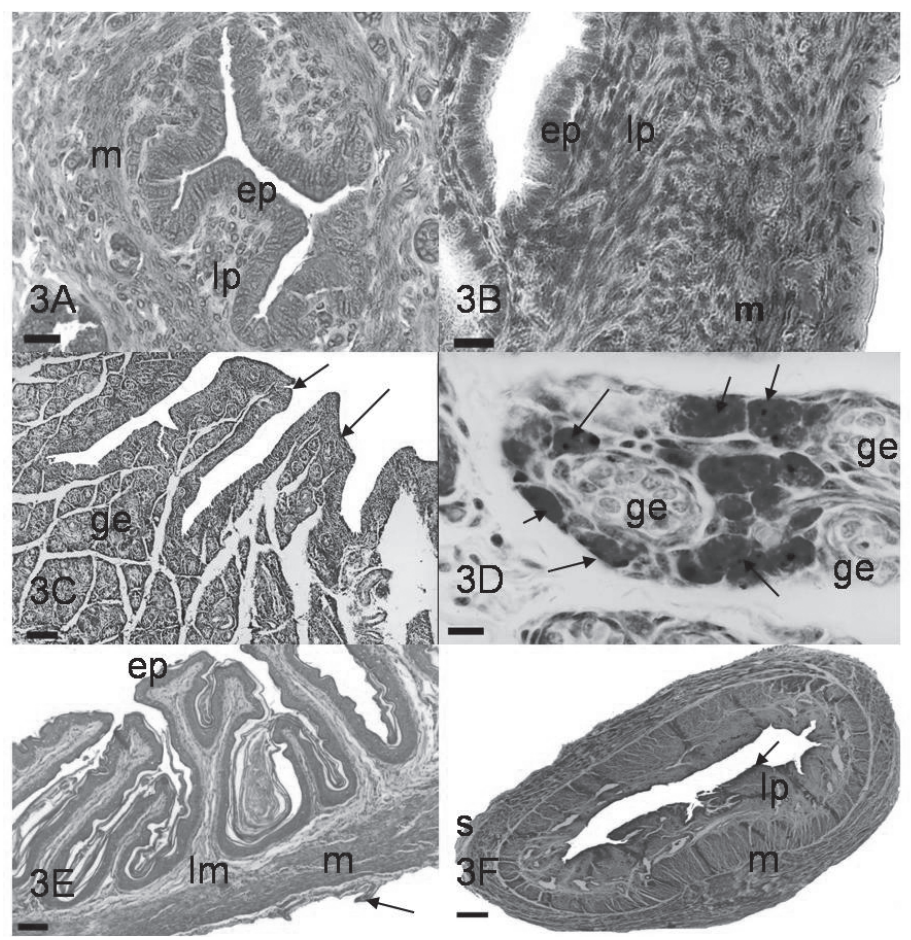

Figura 3 - Em 3A - Fotomicrografia da tuba uterina de gambá. Notar o epitélio prismático ciliado (ep), lâmina própria (Ip) e camadas musculares $(\mathrm{m}) \mathrm{HE}$, barra $=90 \mu \mathrm{m}$. Em 3B - Fotomicrografia da tuba uterina evidenciando o epitélio prismático ciliado (ep) e lâmina própria (lp) e musculares $(\mathrm{m})$ tricromo de Masson, barra $=20 \mu \mathrm{m}$. Em 3C - Fotomicrografia do útero notar as projeções da mucosa (setas) e as glândulas endometriais (ge) tricromo de Masson, barra $=90 \mu \mathrm{m}$. Em 3D, fotomicrografia em detalhe de glândulas endometriais (ge) e células rodeando estas glândulas fortemente marcadas pela reação histoquímica de PAS (setas) barra $=11 \mu \mathrm{m}$. $3 \mathrm{E}-$ Fotomicrografia da vagina lateral evidenciando a mucosa pregueada e epitélio pavimentoso estratificado queratinizado $(\mathrm{ep}) \mathrm{HE}$ barra $=20 \mu \mathrm{m}$. $3 \mathrm{~F}-$ Fotomicrografia panorâmica da pseudovagina. Notar lâmina própria (lp), camadas musculares (m) e serosa (s) $\mathrm{HE}$, barra $=220 \mu \mathrm{m}$

sendo o endométrio a mais interna formada por epitélio simples prismático e repleto de glândulas endometriais associadas ao tecido conjuntivo subjacente. O miométrio é a camada muscular lisa, que se apresentou organizada pelas seguintes túnicas: circular interna e longitudinal externa; o perimétrio, a camada mais externa era formada por serosa ou adventícia dependendo da localização na cavidade abdominal ou pélvica respectivamente (Figura 3). O endométrio era muito espesso, repleto de glândulas e ricamente vascularizado apresentando, portanto, características semelhantes às demais espécies. A área proliferativa do epitélio uterino da espécie Monodelphis domestica é semelhante à de outras espécies de mamíferos, apresentando ondulações e reentrâncias arredondadas ${ }^{8,9}$, o que difere nos Didelphis sp. Pela característica encontrada na área proliferativa completamente irregular com grande quantidade de glândulas e proliferação tecidual da mucosa, o que conferiu a esta região aspecto diferenciado com inúmeras saliências. (Figura 3).

O complexo vaginal era formado por duas vaginas laterais e uma pseudovagina. As duas vaginas laterais posicionavam-se cuadaumente aos comos uterinos e lateralmente à pseudovagina. $\mathrm{O}$ tamanho das vaginas laterais variavam conforme o grau de maturidade da fêmea, as fêmeas que possuíam vaginas mais evidentes eram aquelas reprodutivamente maduras ou multíparas e as que apresentavam vaginas pouco desenvolvidas eram fêmeas jovens ${ }^{6}$ este fato entra em concordância com os nossos achados (Figura 1). A pseudovagina localizava-se no plano mediano e cranialmente 
ligava-se com os cornos uterinos juntamente com as vaginas laterais formando o seio vaginal cranial. Caudalmente, estas três estruturas (vaginas laterias e pseudovagina), voltavam a se encontrar formando então o chamado seio vaginal caudal. $O$ seio vaginal caudal ligava-se a cérvix, que, por sua vez, também caudalmente, unia-se, finalmente, ao seio urogenital (Figura 1). O seio urogenital assemelhou-se conforme decrito descrito em outras espécies de marsupiais. ${ }^{3,5,15}$ Nesta estrutura, cranialmente, abria-se o óstio cervical e também o óstio urinário e o óstio intestinal mais caudalmente, fato este, que nos permitiu utilizar para sua porção mais caudal a denominação de pseudocloaca. ${ }^{2,9}$

A mucosa das vaginas laterais do gambá se apresentou muito pregueada e constituída por epitélio pavimentoso estratificado queratinizado e tecido conjuntivo frouxo. As camadas musculares dividiam-se nas seguintes camadas: circular interna e longitudinal externa; a camada serosa se apresentou muito vascularizada (Figura 3).

A pseudovagina, também conhecida como canal do parto era formada por epitélio pavimentoso estratificado não queratinizado; lâmina própria; camadas musculares e serosa (Figura 3).

Observou-se no seio vaginal epitélio cilíndrico, cuja mucosa era pregueada, porém na região próxima ao óstio cervival das vaginas, o epitélio era pavimentoso estratificado não queratinizado. Logo abaixo do epitélio, notouse a lâmina própria constituída de tecido conjuntivo frouxo, em sequencia, constatouse a camada muscular lisa entremeada ao tecido conjuntivo e a túnica serosa. Neste mesmo órgão na região próxima à abertura do óstio uretral, o epitélio era de transição (Figura 4).

O seio urogenital possuía lâmina própria muito vascularizada (Figura 4). $\mathrm{Na}$ porção ventral da abertura urogenital externa havia áreas de tecido erétil, formando o tubérculo genital, estrutura esta semelhante ao clitóris.

\section{Conclusões}

Os órgãos genitais de Didelphis sp. assemelham-se macro e microscopicamente aos dos demais marsupiais, porém diferem do mamíferos domésticos; os folículos ovarianos podem ser mono ou poliovulares;

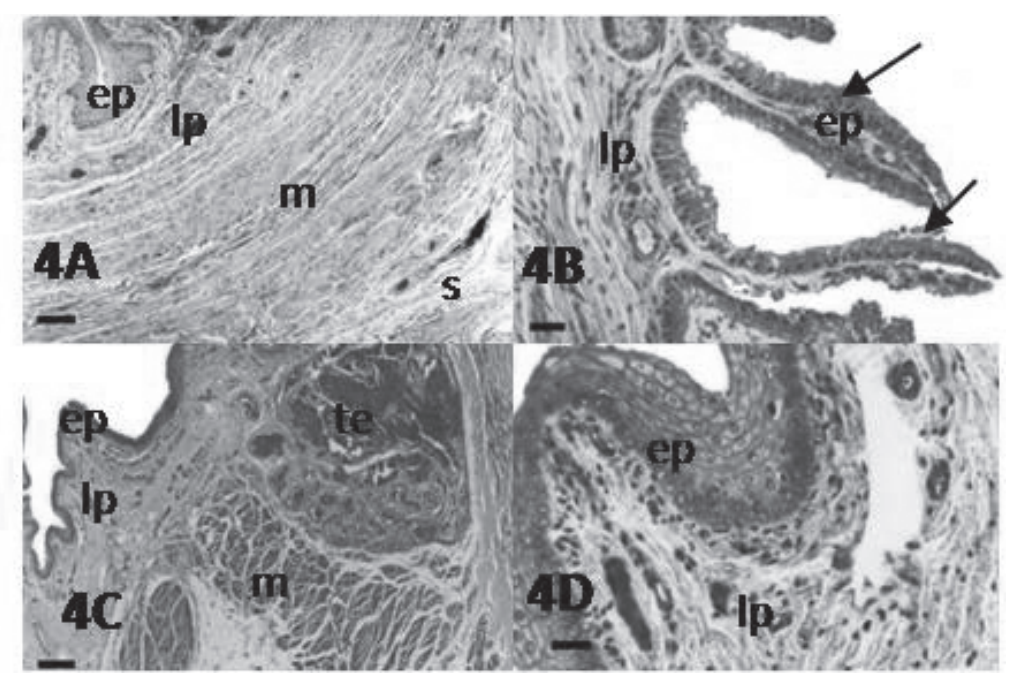

Figura 4 - Em 4A - Fotomicrografia do seio vaginal evidenciando os estratos murais: o epitélio estratificado pavimentoso semelhante a vagina quando próximo à este órgão (ep), lâmina própria (lp), camadas musculares $(\mathrm{m})$ e serosa $(\mathrm{s})$ tricromo de Masson, barra $=90 \mu \mathrm{m} .4 \mathrm{~B}-$ Fotomicrografia do seio vaginal: epitélio cilíndrico simples (ep), com células apresentando na porção apical característica secreção com presença de vacúolos (setas), lâmina própria (Ip) HE, barra $=20 \mu \mathrm{m}$. 4C - Fotomicrografia do seio urogenital: epitélio de transição (ep), lâmina própria (lp), camadas musculares (m) e tecido erétil (te) HE, barra $=220 \mu \mathrm{m} .4 \mathrm{D}$ - Fotomicrografia do seio urogenital: epitélio de transição (ep) e lâmina própria (lp) $\mathrm{HE}$, barra $=20 \mu \mathrm{m}$ 


\section{Morphological aspects of genital female of the opossum (Didelphis sp.)}

\section{Abstract}

Eight reproductive systems of opossum females of had been collected (Didelphis sp). Five, had been destined to macrocospic study and three to the microscopical study. These animals were died and fixeded in the Department of Anatomy of the UNIfeob, with formaldehyde $10 \%$ from Araçatuba scientific creator - IBAMA. For macrocospic analysis, the reproductive systems had been removed, keeping to its positions "in situ" and were carried through the photographic documentation for macrocospic results. For the microscopical study, the reproductive system was processed routinely by the technique of inclusion in similar of paraffin and cut with $5 \mu \mathrm{m}$ thickness, and the cuts had been stained in HE, Toluidin blue, Picrosirius, PAS (periodic acid Shiff reaction) and tricromo de Masson ${ }^{16,17}$. The feminine reproductive system of the opossum was compose for two ovaries, double uterus, two lateral vagins and between these a pseudovaginal canal, these three structures if they join forming the urogenital sinus locking up in a "pubic mount" or genital tubercle, forming an internal common opening to the anus and vulva, call of pseudocloaca or urogenital sinus. Microscopically the ovarios were functional with mono and poliovulares follicles. The uterine tube was characteristic, coated for ciliad prismatic epithelium. The uterine horns had presented epithelium of ciliad prismatic covering. The urogenital sinus presented three tubular structures. Vulva presented the same characteristics of the skin.

\section{Referências}

1 DYCE, K. M.; SACK, W. O.; WENSING, C. J. G. Tratado de anatomia veterinária. 2. ed. Rio de Janeiro: Guanabara Koogan, 1998. 663 p.

2 HILDEBRAND, D. M. Análise da estrutura dos vertebrados. São Paulo: Atheneu, 1995. 700 p.

3 FREYER, C.; ZELLER, U.; RENFREE, M. B. Ultrastucture of the placenta of the tammar wallaby, Macropus eugenii: comparison with the grey shorttailed opossum, Monodelphis domestica. Journal of Anatomy, v. 201, n. 2, p. 101-119, 2002.

4 HICKMAN JR., C. P.; ROBERTS, L. S.; LARSON, A. Princípios integrados de zoologia. 11. ed. Rio de Janeiro: Guanabara Koogan, 2004. 846 p.

5 RENFREE, M. B.; TYNDALE-BISCOE, C. H. Intrauterine Development after diapause in the marsupial Macropus eugenii. Developmental biology, v. 32, n. 1, p. 28-40, 1973.

6 POUGH, F. H.; JANIS, C. M.; HEISER, J. B. A vida dos vertebrados. 3. ed. São Paulo: Atheneu, 2003.

7 ZELLER, U.; FREYER, C. Early ontogeny and placentation of the grey short-tailed opossum, Monodelphis domestica (Didelphidae: Marsupialia): contribution to the reconstruction of the marsupial
Key words: Opossum. Didelphis $s p$. Reproduction. Morphology. morphotype. Journal Zoological Systematization Evolution Research, v. 39, n. 3, p. 137-158, 2001.

8 WICK, R.; KRESS, A. Ultrastructural changes in the uterine luminal and glandular epithelium during the oestrous cycle of the marsupial Monodelphis domestica (Grey Short-Tailed Opossum). Cells Tissues Organs, v. 170, p. 111-131, 2001.

9 WICK, R.; KRESS, A. Ultrastructural changes in the cervical epithelium during the estrous cycle of the marsupial Monodelphis domestica (Grey Short-Tailed Opossum). Cells Tissues Organs, v. 171, p. 162-176, 2002.

10 REGLI, C.; KRESS, A. Changes in the epithelium of the vaginal complex during the estrous cycle of the marsupial Monodelphis domestica. Cells Tissues Organs, v. 172, p. 276-296, 2002.

11 HARDER, J. D.; STONEROOK, J. M.; PONDY, J. Gestation and placentation in two new world opossums: Didelphis virginiana and Monodelphis domestica. The Journal of Experimental Zoology, v. 266, p. 463-479, 1993

12 BEHRINGER, R. R.; EAKIN, G. S.; RENFREE, M. B. Mamamalian diversity: gametes, embryos and reproduction. Reproduction, Fertility and Development, v. 18, p. 99-107, 2006.

13 BANKS, W. J. Histologia veterinária aplicada. 2. 
ed. São Paulo: Manole, 1992. 560 p.

14 JUNQUEIRA, L. C.; CARNEIRO, J. Histologia básica. 10. ed. Rio de Janeiro: Guanabara Koogan, 2004. 448 p.

15 RENFREE, M. B. Ovariectomy during gestation in the american opossum, Didelphis marsupials virginiana. Journal of Reproduction and Fertility, v. 39, p.127-130, 1974.

16 BEHMER, O. A.; TOLOSA, E. M. C.; NETO, A. G. F. N. Manual de técnicas para histologia normal e patológica. São Paulo: EDART, 1976. 241 p.

17 JUNQUEIRA, L. C.; BIGNONAS, G.; BRETAN, R. R. Picrosirius staing plus polarizacion microscopy, a specifc method for collagen detection in the tissue sections. Histochem Journal, v. 11, n. 4, p. 447-455, 1979 . 